\title{
A DISCIPLINA DE LIBRAS EM CURSOS DE LICENCIATURA EM EDUCAÇÃOO FÍSICA
}

\author{
LIBRAS IN PHYSICAL EDUCATION TEACHER TRAINING COURSES
}

\section{LA ASIGNATURA DE LIBRAS EN LAS CARRERAS DE FORMACIÓN DEL PROFESSORADO DE EDUCACIÓN FÍSICA}

\author{
Elisabeth Rosseto* \\ Elizete Gonçalves Ribeiro ** \\ Rodrigo Zini ${ }^{* * *}$
}

\section{Resumo}

O objetivo deste artigo é analisar títulos, carga-horária e conteúdos programáticos da disciplina de Libras em cursos de licenciatura em Educação Física. Para tanto, optou-se por uma pesquisa de caráter descritivo, por meio de análise documental, com a utilização do plano do ensino da disciplina de Libras, ofertada por três cursos presenciais de licenciatura em Educação Física da região Oeste do Paraná. Foram constatados equívocos no título da disciplina e insuficiência em sua carga horária. Em relação aos conteúdos abordados, há três categorias temáticas: o ensino de Libras; surdez e a pessoa surda; aspectos educacionais da pessoa surda. A categoria mais expressiva é a do ensino de Libras, ressaltando a importância de os professores terem conhecimento da língua e das características linguísticas e culturais dos alunos surdos.

Palavras-chave: Libras. Formação de professores. Educação Física.

\section{Introdução}

Os alunos surdos apresentam características singulares, decorrentes principalmente de suas condições linguísticas e culturais (SILVA; SILVA, 2016). Nesse sentido, a escolarização desses alunos torna-se um desafio para os sistemas educacionais que, a partir de uma perspectiva inclusiva, devem proporcionar condições adequadas para sua aprendizagem. A trajetória histórica da escolarização dos surdos é marcada por estigma e exclusão. Durante a

\footnotetext{
* Doutora em Educação pela Universidade Federal do Rio Grande do Sul (2009). Professora Associada do Programa de Pós-Graduação em Educação da Universidade Estadual do Oeste do Paraná. E-mail: erossetto2013@gmail.com

** Mestre em Educação pela Universidade Estadual do Oeste do Paraná. E-mail: isis.ilson.eliz@gmail.com

*** Mestre em Educação pela Universidade Estadual do Oeste do Paraná. E-mail: $\underline{\text { r_zini@ @hotmail.com }}$
} 
Antiguidade e a Idade Média os surdos eram considerados não educáveis. Só recebiam algum tipo de instrução os que eram filhos de ricos e nobres (LACERDA, 1998). As primeiras experiências educativas relacionadas aos surdos surgiram a partir do século XVI, por meio de métodos oralistas, com a utilização da leitura orofacial. Buscava-se a "normalização" desses sujeitos, fazendo com que eles agissem como ouvintes (LACERDA, 1998).

Um dos responsáveis pela mudança histórica da educação dos surdos foi o abade Charles Michel de l'Épée, que aprendeu com os surdos pobres das ruas de Paris a língua de sinais e, introduziu esse sistema de signos na educação de outros surdos. O abade francês foi um dos primeiros representantes da abordagem gestualista, que permitia a comunicação pelo canal viso-gestual. Em 1799 fundou a primeira escola de surdos do mundo, onde as aulas deixaram de ser individuais e passaram a ser coletivas (DUARTE et al., 2013).

As discussões em relação aos métodos de ensino para os alunos surdos levaram à realização do I Congresso Internacional de Milão. Em 1880, no II Congresso Internacional de Milão, pesquisadores oralistas, em defesa a sua abordagem, apresentaram surdos com grandes avanços em relação à fluência da fala. Assim, após votação, optou-se por proibir a utilização de gestos e sinais para a educação dos surdos e padronizar a abordagem oralista (LACERDA, 1998).

A abordagem oralista prevaleceu até a década de 1960, pois, sem considerar as questões peculiares da linguagem desses sujeitos, dificultava-se a aprendizagem e, em muitos casos, ocasionava repetência e desistência da escola. Ao mesmo tempo, realizavam-se pesquisas envolvendo a língua de sinais para a educação dos surdos. Dessa forma, adotou-se a abordagem da comunicação total, que envolvia os gestos naturais, a língua de sinais, o alfabeto manual e as expressões faciais (HONORA, 2014).

No final da década de 70, nos Estados Unidos, iniciou-se o movimento das pessoas surdas para reivindicar o direito de usar a língua de sinais como primeira língua e, de apreender a língua majoritária como segunda língua. Essa abordagem ficou conhecida como bilingüismo que, de acordo com as pesquisas, tem se mostrado a proposta mais adequada para a escolarização das pessoas surdas (JESUS, 2015).

No Brasil, o bilingüismo começou a ser utilizado no processo de escolarização das pessoas surdas a partir da década de 1980. A Língua Brasileira de Sinais, Libras, foi reconhecida como meio legal de comunicação e expressão somente em 24 de abril de 2002, através da Lei $\mathrm{n}^{\circ} 10.436$, que garantiu por parte do poder público em geral e empresas 
concessionárias de serviços públicos, formas institucionalizadas de apoio ao seu uso e difusão (BRASIL, 2002).

A Libras é um sistema lingüístico de natureza visual-motora, com estrutura gramatical própria, oriunda das comunidades de pessoas surdas no Brasil (BRASIL, 2002). A Libras pode ser considerada um mecanismo necessário para inclusão, pois possibilita a comunicação entre as pessoas surdas, além de também possibilitar a comunicação com a comunidade ouvinte. Santana (2013) destaca que a institucionalização e, posteriormente, o reconhecimento legal da Libras foi um passo importante para conquista dos direitos das pessoas surdas na sociedade. A partir da difusão da Libras que os surdos passaram a ter acesso às informações e a partilharem idéias, desejos e sentimentos.

De forma semelhante, a Política Nacional de Educação Especial, na Perspectiva da Educação Inclusiva (BRASIL, 2008), ressalta que, como alternativa para superar a lógica da exclusão, a educação deve estar fundamentada nos direitos humanos, defendendo o direito de os alunos estarem juntos, de participarem e aprenderem sem nenhum tipo de discriminação. Sob essa ótica, a escolarização dos alunos surdos deve ser realizada em escolas regulares, com o auxilio do tradutor/intérprete de Libras/língua portuguesa e atendimento educacional especializado, tanto na modalidade oral e escrita quanto na língua de sinais (BRASIL, 2008).

Nesse sentido, considera-se que o aluno surdo seja capaz de apreender os mesmos conteúdos que os demais alunos. Deve-se levar em conta, contudo, as suas singularidades lingüísticas e, dessa forma, assegurar o uso da língua de sinais para garantir o seu desenvolvimento. Conforme apontam Silva e Silva (2016), não se deve acreditar, ingenuamente, que a língua de sinais será a solução para todos os problemas educacionais referentes à inclusão dos alunos surdos, uma vez que não é tarefa fácil trabalhar em um ambiente onde existem diferentes sistemas linguísticos.

Em relação ao atendimento dos alunos surdos em escolas regulares, Jesus (2015) ressalta que muitos professores, por falta de conhecimento, deixam para o intérprete as funções de ensinar e de ajudar a desenvolver as atividades propostas para os alunos surdos, omitindo-se assim dessa obrigação educacional. É necessário, portanto, e imprescindível, que professores tenham conhecimento sobre a Libras, assim como das características linguísticas e culturais desses alunos.

Sobre a Libras e a formação dos professores, o decreto 5.626, de 22 de dezembro de 2005, em seu artigo $3^{\circ}$, assegura que a Libras deve ser inserida como disciplina curricular obrigatória nos cursos de formação de professores para o exercício do magistério, em nível 
médio e superior, em instituições de ensino públicas e privadas do país (BRASIL, 2005). Com a aprovação do decreto notou-se um avanço em relação à expansão da disciplina de Libras nos cursos de formação inicial de professores, que a inseriram na grade curricular em cumprimento à legislação. No entanto, o decreto não estabelece carga horária e conteúdos a serem abordados nessa disciplina. Ficou sob a responsabilidade de cada instituição de ensino estabelecer esses critérios. Diante do exposto, levanta-se uma questão: como as disciplinas de Libras estão organizadas nos cursos de formação inicial de professores? Para responder a essa pergunta, objetiva-se analisar, neste artigo, os planos de ensino das disciplinas de Libras dos cursos de licenciatura em Educação Física da região Oeste do Paraná, tendo em vista o título, carga horária e conteúdos ofertados por tais disciplinas.

\section{Caminhos metodológicos}

Diante do objetivo proposto, optou-se por uma pesquisa de caráter descritivo (GIL, 2008). Através da análise documental dos planos de ensino, buscou-se descrever as características principais da disciplina Libras, tal como é ofertada nos cursos de licenciatura em Educação Física, na modalidade de ensino presencial, da região Oeste do Paraná.

Para a seleção da amostra dos cursos que fizeram parte do estudo, foi realizado um levantamento de todos os cursos presenciais ofertados na região Oeste do Paraná, por meio do cadastro do e-MEC de Instituições e Cursos de Educação Superior ${ }^{1}$. Foram encontrados seis cursos em funcionamento no ano de 2017. Após contatos por telefone e por email com os coordenadores desses cursos, foram enviadas cartas de apresentação da pesquisa e três instituições aceitaram participar do estudo: uma universidade pública, um centro universitário privado e uma faculdade privada. A coleta de dados se deu através dos coordenadores dos cursos que disponibilizaram os planos de ensino e autorizaram a sua utilização. Durante a apresentação dos dados, por questões éticas, optou-se em representar os cursos por meio de letras, a saber: A, B e C.

Tendo em vista o objetivo desta pesquisa, os dados selecionados para análise foram: o título da disciplina, carga-horária e os conteúdos programáticos, dados disponíveis nos planos de ensino. O título e a carga horária das disciplinas foram organizados em um quadro, com a finalidade de facilitar a visualização e comparação. Para análise dos conteúdos programáticos, primeiramente os dados selecionados foram transcritos em um quadro e realizou-se a leitura do conjunto dos dados com a finalidade de familiarização com as informações. Em seguida, os conteúdos programáticos foram separados em outro quadro com a identificação da fonte. 
A partir desse quadro, foi possível identificar as categorias temáticas, agrupando os trechos retirados dos planos de ensino conforme a semelhança do seu conteúdo. Assim, elaborou-se um quadro explicativo, com os nomes das categorias temáticas, descrições e exemplos dos trechos destacados, com citações diretas da fonte dos dados. Por fim, para apresentação e análise das categorias temáticas, com o intuito de identificar as mais expressivas, utilizou-se a frequência absoluta (f.) e relativa (\%) das categorias por disciplina e a total (soma de todos as disciplinas), organizadas em um quadro.

\section{Resultados e discussões}

Os três cursos de licenciatura em Educação Física pesquisados ofertam a disciplina em sua matriz curricular, de forma obrigatória. Nota-se que todos estão em conformidade com o decreto $n^{\circ} 5626 / 05$, que estabelece a obrigatoriedade dessa disciplina em cursos de formação de professores (BRASIL, 2005).

Com relação à oferta da disciplina em cursos de graduação, Giroto et al. (2016), ao pesquisarem 46 matrizes curriculares de cursos de Pedagogia, licenciaturas e fonoaudiologia de uma IES pública do estado de São Paulo, verificaram que somente quatro cursos, ou seja 9\%, ofertavam a disciplina de Libras e em um deles a oferta era de caráter optativo. Louzada (2017), em sua dissertação, investigou a organização dos conteúdos curriculares da Educação Especial em seis cursos de Educação Física ofertados em IES públicas do estado de São Paulo. Com relação à disciplina de Libras, identificou quatro cursos que a ofertavam, enquanto dois não apresentavam tal disciplina em suas matrizes curriculares.

Assim, os cursos pesquisados cumprem a legislação no que se refere à oferta da disciplina de Libras, fato que não foi constatado em outros estudos similares (GIROTO et al. 2016; LOUZADA, 2017). Os dados coletados, disponíveis no quadro 1, referem-se ao título da disciplina e à carga horária:

Quadro 1 - Curso, título e carga horária das disciplinas de Libras

\begin{tabular}{|l|l|l|}
\hline Curso & Título da disciplina & Carga horária \\
\hline A & Libras & 68 \\
\hline B & Introdução à Linguagem de Sinais & 44 \\
\hline C & Língua Brasileira de Sinais & 36 \\
\hline Média & & 49,3 \\
\hline
\end{tabular}

Fonte: Plano de Ensino das disciplinas de Libras. 
No tocante ao título, as disciplinas dos cursos A e C apresentam nomenclatura similar, uma vez que o título da disciplina A está no formato de sigla, enquanto o título da disciplina C aparece por extenso "Língua Brasileira de Sinais". No caso do título da disciplina B Introdução à Linguagem de Sinais cabe salientar a observação realizada por Oviedo (1996), que recomenda a adoção do termo "língua" ao invés de "linguagem", pois considera-se "linguagem" a capacidade do ser humano em se comunicar por meio de um sistema de signos, enquanto "língua" se refere a um sistema específico de signos utilizados por um grupo para a comunicação. No que se refere à carga horária, há uma diferença entre as disciplinas, pois a disciplina A é a que apresenta maior carga horária, 68 horas, ao passo que nas disciplinas B e C a carga horária é de 44 e 36 horas, respectivamente.

Dados semelhantes também foram encontrados no estudo feito por Mercado (2012) em cursos de Pedagogia de cinco universidades, nos quais a carga horária também variou de modo expressivo. No caso das disciplinas pesquisadas neste trabalho, essas apresentaram as seguintes cargas horárias: 20, 40, 40, 45 e 88 horas aula. No estudo de Maeda (2012) com 22 acadêmicos de Pedagogia que freqüentaram, na graduação, a disciplina de Libras com 64 horas, os entrevistados consideraram a carga horária insuficiente.

Lopes et al. (2016) defendem a ampliação da carga horária destinada à disciplina de Libras, pois acreditam que a consolidação da formação de professores deve ocorrer a partir de um contexto teórico e prático consistente. Portanto, os cursos de formação devem ofertar subsídios para que os futuros profissionais possam obter conhecimento suficiente acerca de como atender seus alunos utilizando-se da Língua Brasileira de Sinais.

Como o decreto que regulamenta a inserção da disciplina de Libras nos cursos de formação de professores não estabelece carga horária mínima para a disciplina, as instituições a oferecem com carga horária muito limitada, o que impossibilita os alunos de terem acesso aos necessários conhecimentos de Libras. Entende-se que uma única disciplina não dará ao aluno suporte suficiente para que ele consiga se comunicar em Libras, mas esse é um espaço importante para divulgação da língua e a apropriação, pelo aluno, dos elementos básicos que, certamente, irão contribuir para o trabalho do futuro professor de turmas com alunos surdos.

Nesse sentido, Almeida e Vitaliano (2012) destacam que os conhecimentos sobre a estrutura linguística da Libras são fundamentais, pois, além de possibilitarem a interação entre professor e aluno, instrumentam o docente na busca de explicações mais claras e sucintas, facilitando o trabalho do tradutor-intérprete e, consequentemente, o aprendizado do aluno 
surdo. Em relação aos conteúdos programáticos que estão presentes nos planos de ensino constatou-se a existência de 3 categorias temáticas, descritas no quadro a seguir.

Quadro 2 - Categorias temáticas

dos conteúdos dos planos de ensino das disciplinas de Libras

\begin{tabular}{|c|c|c|}
\hline Categoria & Descrição & Exemplo \\
\hline $\begin{array}{l}\text { Ensino de } \\
\text { Libras }\end{array}$ & $\begin{array}{l}\text { Conteúdos sobre } \\
\text { os aspectos } \\
\text { linguísticos da } \\
\text { Libras, voltados } \\
\text { ao ensino e } \\
\text { apropriação da } \\
\text { língua }\end{array}$ & $\begin{array}{l}\text { "Sinais contextualizados relacionados à: frutas, } \\
\text { cores, alimentação e objetos" (trecho retirado do } \\
\text { plano de ensino da disciplina A) } \\
\text { "Sinais de Identificações pessoais e pronomes } \\
\text { pessoais" (trecho retirado do plano de ensino da } \\
\text { disciplina B) } \\
\text { "Parâmetros para a confecção de um sinal na } \\
\text { Língua de Sinais" (trecho retirado do plano de } \\
\text { ensino da disciplina C) }\end{array}$ \\
\hline $\begin{array}{l}\text { Surdez e a } \\
\text { pessoa surda }\end{array}$ & $\begin{array}{l}\text { Conteúdos } \\
\text { referentes aos } \\
\text { aspectos } \\
\text { históricos, } \\
\text { conceituais e } \\
\text { descritivos da } \\
\text { surdez e da } \\
\text { pessoa surda }\end{array}$ & $\begin{array}{l}\text { "Aspectos políticos e teóricos da surdez no } \\
\text { Brasil" (trecho retirado do plano de ensino da } \\
\text { disciplina A) } \\
\text { "Cultura e Identidade Surda" (trecho retirado do } \\
\text { plano de ensino da disciplina B) } \\
\text { "Definição de surdez e problemas auditivos" } \\
\text { (trecho retirado do plano de ensino da disciplina } \\
\text { C) }\end{array}$ \\
\hline $\begin{array}{l}\text { Aspectos } \\
\text { educacionais } \\
\text { da pessoa } \\
\text { surda }\end{array}$ & $\begin{array}{l}\text { Conteúdos } \\
\text { designados ao } \\
\text { estudo dos } \\
\text { aspectos } \\
\text { educacionais dos } \\
\text { alunos com } \\
\text { surdez }\end{array}$ & $\begin{array}{l}\text { "O processo de aprendizagem e desenvolvimento } \\
\text { da pessoa surda na abordagem vigotskiana" } \\
\text { (trecho retirado do plano de ensino da disciplina } \\
\text { A) } \\
\text { "Filosofias educacionais para surdos" (trecho } \\
\text { retirado do plano de ensino da disciplina B) } \\
\text { "Educação dos surdos no Brasil e no mundo } \\
\text { Educação especial x educação inclusiva" (trecho } \\
\text { retirado do plano de ensino da disciplina C) }\end{array}$ \\
\hline
\end{tabular}

Fonte: elaborado pelo pesquisador (2018).

A partir das categorias temáticas que emergiram dos conteúdos programáticos, presentes nos planos de ensino, são apresentadas, no quadro 3, as frequências relativa (\%) e absoluta (f) da incidência das categorias nas disciplinas pesquisadas. 
Quadro 3 - Frequência das categorias temáticas dos conteúdos dos planos de ensino das disciplinas de Libras

\begin{tabular}{|c|c|c|c|c|}
\hline Disc & $\underbrace{\text { Categorias }}_{\text {plinas }}$ & $\begin{array}{c}\text { Ensino de } \\
\text { Libras }\end{array}$ & $\begin{array}{c}\text { Surdez e a } \\
\text { pessoa surda }\end{array}$ & $\begin{array}{c}\text { Aspectos } \\
\text { educacionais da } \\
\text { pessoa surda }\end{array}$ \\
\hline $\mathbf{A}$ & f. & 22 & 4 & 8 \\
\hline & $\%$ & 64,7 & 11,8 & 23,5 \\
\hline B & f. & 9 & 6 & 2 \\
\hline & $\%$ & 52,9 & 35,3 & 11,8 \\
\hline $\mathrm{C}$ & f. & 16 & 2 & 3 \\
\hline & $\%$ & 76,2 & 9,5 & 14,3 \\
\hline & f. & 47 & 12 & 13 \\
\hline Total & $\%$ & 65,3 & 16,7 & 18 \\
\hline
\end{tabular}

Fonte: elaborado pelo pesquisador (2018).

Os dados demonstram que a maior parte dos conteúdos estão relacionados ao ensino da Libras, perfazendo um total de 65,3\%. Nessa categoria, a disciplina que apresentou maior porcentual foi a C, com 76,2\%. No total, com a somatória das três disciplinas, observa-se que a categoria destinada aos aspectos educacionais da pessoa surda esteve presente em $18 \%$ dos conteúdos, essa categoria é mais expressiva na disciplina A, com 23,5\%. A categoria relacionada à surdez e à pessoa surda, no total, obteve 16,7\%, não havendo uma diferença muito elevada para a categoria relacionada a aspectos educacionais. A disciplina B, por sua vez, apresentou a frequência mais elevada em comparação com as outras para essa categoria, com $35,3 \%$.

Outros estudos, que também verificaram os planos de ensino da disciplina de Libras (LOUZADA, 2017; ADAMS, 2017; GIROTO et al. 2016), constataram a não existência de um padrão nos conteúdos e na carga horária. Esse fato pode ser explicado pela recente inserção da disciplina nos cursos de graduação. Embora o decreto n ${ }^{\circ} 5.626$ seja de dezembro de 2005, passados mais de dez anos, a disciplina ainda não se consolidou nas grades curriculares.

Sobre o ensino de Libras no ensino superior e à forma como essa disciplina tem sido ministrada atualmente, Giroto et al. (2016, p.753) afirmam que "tem sido destacada a presença de conteúdos sobre a cultura surda e as necessidades educacionais de usuários desta modalidade linguística, juntamente com conhecimentos básicos e introdutórios em termos de sinalização desta língua". Parece evidente que essa disciplina não deve abordar somente o ensino da língua, mas também aspectos referentes ao aluno surdo e às suas especificidades, 
notadamente quando se trata de cursos de formação inicial de professores. À luz de uma proposta educacional inclusiva, na qual os alunos surdos estão inseridos em turmas regulares, conteúdos dessa natureza vão auxiliar os professores no desenvolvimento do trabalho pedagógico.

Nesse sentido, Cruz e Tassa (2012), ao tratarem sobre a inserção da disciplina de Libras, ressaltam que, além da disciplina ofertar uma ferramenta fundamental para comunicação, também pode promover atividades curriculares que provoquem a reflexão quanto à função do professor no processo de construção de uma escola que tenha uma postura inclusiva frente a diversidade. Ao abordar a inclusão dos alunos, faz-se necessário destacar o artigo 22 do decreto $\mathrm{n}^{\circ} 5.626$ (BRASIL, 2005), que garante aos alunos surdos e com deficiência auditiva:

I - escolas e classes de educação bilíngüe, abertas a alunos surdos e ouvintes, com professores bilíngües, na educação infantil e nos anos iniciais do ensino fundamental;

II - escolas bilíngües ou escolas comuns da rede regular de ensino, abertas a alunos surdos e ouvintes, para os anos finais do ensino fundamental, ensino médio ou educação profissional, com docentes das diferentes áreas do conhecimento, cientes da singularidade lingüística dos alunos surdos, bem como com a presença de tradutores e intérpretes de Libras - Língua Portuguesa.

A disciplina de Libras deveria, portanto, proporcionar informações referentes à singularidade linguística dos alunos surdos, conteúdo que está presente na categoria temática "Surdez e a pessoa surda".

Esta pesquisa levou à constatação de que cada um dos planos de ensino estudados apresentava unidades referentes a esse tema. No plano de ensino da disciplina A encontramse: "Aspectos linguísticos e prática da Libras"; "Mitos e realidades sobre os surdos e a surdez"; "Aquisição da língua de sinais e comunicação com o mundo". No plano de ensino da disciplina B, tem-se o item: "Cultura e Identidade Surda" e no plano de ensino da disciplina C, consta “Aquisição de linguagem”. Percebe-se que em todas as disciplinas há unidades que possibilitam a abordagem das singularidades linguísticas dos alunos surdos, porém, na disciplina A, verificou-se a presença de mais unidades que podem ser relacionadas a essa temática.

É importante que futuros professores tenham consciência da singularidade linguística dos alunos surdos, pois conforme aponta Vigotski (2000) as funções cognitivas e comunicativas envolvidas na linguagem das crianças tornam-se a base para as formas 
superiores do pensamento. No mesmo sentido, Dizeu e Caporali (2005) destacam que é por meio da linguagem que o ser humano se desenvolve e constrói as relações com os outros que estão a sua volta. Contudo, a mesma língua que inclui um indivíduo no convívio social também pode excluí-lo, considerando que as relações que buscará estabelecer dependem dela.

Tendo em vista que o desenvolvimento humano depende da linguagem e da interação entre os sujeitos, é necessário que o aluno surdo adquira e desenvolva essas capacidades. Da mesma forma, cabe ao professor conhecer e respeitar a linguagem natural do aluno que utiliza a linguagem viso-espacial como instrumento para sua aprendizagem, em detrimento da linguagem oral-auditiva que, por muito tempo, lhe foi imposta. Duarte et al. (2013) afirmam que é necessário conhecer as particularidades da cultura e da identidade surda, de modo a propiciar o desenvolvimento das habilidades comunicativas e favorecer a relação entre os surdos e a sociedade. Ter a consciência dessa singularidade linguística é fundamental para que o professor possa mediar adequadamente os processos de ensino e aprendizagem em uma sala de aula com alunos em distintas condições de linguagem.

Ainda sobre as garantias educacionais do decreto n 5.626 (BRASIL, 2005), destacado anteriormente, é necessário evidenciar as questões referentes à educação bilíngue, pois é importante que os futuros professores tenham conhecimento das recomendações educacionais sobre os alunos surdos e de suas possibilidades. Assim, foram destacados trechos extraídos dos planos de ensino, do conteúdo referente a "A educação da pessoa surda": "Bilinguismo e seus diferentes projetos políticos" (trecho retirado do plano de ensino da disciplina A), "Bilinguismo" (trecho retirado do plano de ensino da disciplina $\mathrm{C}$ ).

O "bilinguismo" está presente nos conteúdos das disciplinas A e C, mas não foi identificado na disciplina B, o que se considera uma fragilidade, pois dificilmente conteúdos que não estão previstos na programação dos planos de ensino são discutidos em sala de aula.

Destaca-se que, além de ser uma recomendação legal, o ensino bilíngue caracteriza-se pelo respeito à língua natural dos surdos, ou seja, a língua de sinais, e insere a língua majoritária (em nosso caso o português) como segunda língua. O que se espera é que as aulas sejam ministradas nas duas línguas: na língua de sinais e na modalidade escrita da língua portuguesa (ARAGON; SANTOS, 2015). Conforme Pereira e Vieira (2009) a língua de sinais é de fácil aquisição para os surdos, oferecendo-lhes desenvolvimento lingüístico, afetivo, social, além de construir a base para a aquisição da escrita e da leitura da língua majoritária na sociedade onde vivem. Assim, é relevante que os profissionais envolvidos com a educação tenham conhecimentos sobre o ensino bilíngüe e seus benefícios para os alunos surdos. 
Ademais, por se tratar de disciplinas presentes em cursos de Educação Física, é necessário frisar que a disciplina A é a única entre as três em que foram identificados conteúdos relacionados a aspectos específicos da área, tal como pode ser observado nestes trechos retirados do plano de ensino da disciplina A: "adaptação curricular e de conteúdos da Educação Física para alunos surdos inclusos na Educação Básica"; "o desenvolvimento e aplicação de planos de ensino com adaptações de conteúdos relativas à disciplina de Educação Física"; "estratégias teórico-metodológicas para a disciplina de Educação Física em turmas que contemplem estudantes surdos inclusos".

É fundamental para os futuros professores a inserção nos planos de ensino de temas sobre elaboração, adaptações e estratégias teórico-metodológicas para o ensino de alunos surdos ou com outra deficiência nas aulas de Educação Física. Como afirma Cruz (2005), para se criar um ambiente de aprendizagem que valorize o processo de apropriação do conhecimento sistematizado, é importante que o professor esteja devidamente instrumentalizado para garantir a realização dos objetivos propostos.

\section{Considerações finais}

Adotar as disposições do decreto 5.626, de 2005, nos cursos que objetivam formar professores, no que diz respeito à disciplina relacionada a Libras. é um passo importante para garantir aos alunos surdos escolarização de qualidade, que respeite as suas singularidades. Porém, percebe-se a necessidade urgente de se avançar nos encaminhamentos em relação à forma como essas disciplinas estão organizadas nos currículos dos cursos de licenciatura em Educação Física, principalmente no que se refere à carga horária e aos conteúdos programáticos.

Observou-se nas três disciplinas de Libras ofertadas nos cursos presenciais de licenciatura em Educação Física do Oeste do Paraná, pesquisados neste trabalho, que uma das disciplinas não utiliza a nomenclatura Libras ou Língua Brasileira de Sinais, e sim Linguagem de Sinais o que pode indicar incoerência em relação ao proposto pelo decreto 5.626. Não foi possível observar um padrão entre as três disciplinas em relação à carga horária, pois duas apresentaram uma carga horária considerada insuficiente, entre 36 e 44 horas. Os conteúdos mais frequentes nos planos de ensino são os relacionados ao ensino de Libras, identificandose também temas sobre a surdez e os aspectos educacionais da pessoa surda. Uma das disciplinas pesquisadas não aborda em seus conteúdos programáticos a educação bilíngue, 
ignorando que a proposta educacional mais adequada para os alunos surdos deve estar baseada nesta perspectiva.

Outro fator a ser destacado, é ausência de conteúdos que abordem adaptações e estratégias no ensino da Educação Física para os alunos surdos, pois devido à importância dessa disciplina na formação escolar, faz-se necessário levantar discussões sobre os aspectos metodológicos da disciplina tendo em vista a participação de alunos surdos. Por fim, a ampliação dos estudos sobre a disciplina de Libras nos cursos de licenciatura, bem como, a realização de outras investigações sobre essa temática, são ações que fornecerão subsídios para o aprimoramento da docência de Libras no ensino superior, o que contribuirá, de forma geral, com a aprendizagem de alunos surdos.

\begin{abstract}
This paper aims to analyze the titles, workload, and programmatic content of the Libras subject in undergraduate teaching training courses in Physical Education. In order to so, we opted for a descriptive research, through documental analysis, with the utilization of the teaching plan for Libras, offered by three classroom-based teacher training courses in Physical Education from Paraná's West region. Mistakes were found in the name of the subject and its workload was found insufficient. In relation to the contents taught, there are three thematic categories: the teaching of Libras; deafness and the deaf person; educational aspects of the deaf person. The most expressive category is the one for teaching Libras, highlighting the importance of teachers knowing the language and the linguistic and cultural characteristics of deaf students.
\end{abstract}

Keywords: Libras. Teacher training. Physical Education.

\title{
Resumen
}

El objetivo de este artículo es analizar títulos, carga horaria y contenidos programáticos de la asignatura de Libras en carreras para formación del profesorado de Educación Física. Para ello, se optó por una investigación de carácter descriptivo, por medio de análisis documental, con la utilización del plan de enseñanza de la asignatura de Libras, ofrecida por tres cursos presenciales para el profesorado de Educación Física de la región Oeste de Paraná. Se constataron equívocos en el título de la asignatura e insuficiencia en su carga horaria. En cuanto a los contenidos tratados, hay tres categorías temáticas: la enseñanza de Libras; sordera y la persona sorda; aspectos educativos de la persona sorda. La categoría más expresiva es la de la enseñanza de Libras, prevaleciendo la importancia de que los profesores adquieran conocimientos de la lengua y de las características lingüísticas y culturales de los alumnos sordos.

Palabras clave: Libras. Formación del profesorado. Educación Física. 


\section{Referências}

ADAMS, Fernanda Welter. A disciplina de LIBRAS na formação inicial de professores de ciências da natureza. In: XIII CONGRESSO NACIONAL DE EDUCAÇÃO. 2017. Curitiba. Anais. Curitiba: EDUCERE, 2017. Disponível em: http://educere.pucpr.br/p7 lanais.html?titulo=\&edicao=6 Acesso em: 11 set 2018.

ALMEIDA, Josiane Junia Facundo de; VITALIANO, Célia Regina. A disciplina de Libras na formação inicial de pedagogos: experiências dos graduandos. In: IX SEMINÁRIO ANPEDSUL. Anais. Caxias do Sul: ANPED, 2012.

ARAGON, Carmelina Aparecida; SANTOS, Isabela Bagliotti. Deficiência auditiva/surdez: conceitos, legislações e escolarização. Educação, Batatais, v. 5, n. 2, p. 119-140. 2015.

BRASIL. Lei no 10.436, de 24 de abril de 2002. Dispõe sobre a Língua Brasileira de Sinais Libras e dá outras providências. Diário Oficial [da] União, Brasília, DF, 25 abr.2002.

Disponível em: <http://www.planalto.gov.br/ccivil_03/leis/2002/L10436.htm>. Acesso em: 10 set. 2017.

BRASIL. Política Nacional de Educação Especial na Perspectiva da Educação Inclusiva. Ministério da Educação. Secretaria de Educação Especial. Brasília, 2008. Disponível em: http://portal.mec.gov.br/index.php?option=com_docman\&view=download\&alias $=16690$ politica-nacional-de-educacao-especial-na-perspectiva-da-educacao-inclusiva05122014\&Itemid=30192. Acesso em: 15 set. 2017.

BRASIL. Decreto $n^{0}$ 5.626, de 22 de dezembro de 2005. Regulamenta a Lei $n^{\circ} 10.436$, de 24 de abril de 2002, que dispõe sobre a Língua Brasileira de Sinais - Libras, e o art. 18 da Lei no 10.098, de 19 de dezembro de 2000. Diário Oficial [da] União, Brasília, DF, 23 dez. 2005.

Disponível em: http://www.planalto.gov.br/ccivil_03/_ato20042006/2005/decreto/d5626.htm. Acesso em: 15 set. 2017.

CRUZ, Gilmar de Carvalho. Formação continuada de professores de educação física em ambiente escolar inclusivo. Campinas, 2005. Tese (Doutorado em Educação Física). 254p. - Faculdade de Educação Física da Universidade Estadual de Campinas, Campinas, São Paulo, 2005.

CRUZ, Gilmar de Carvalho; TASSA, Khaled Omar Mohamad El. A inclusão escolar na formação de professores: perspectivas da educação física. In: III CONGRESSO IBERO AMERICANO DE POLÍTICA E ADMINISTRAÇÃO DA EDUCAÇÃO. 2012. ZaragozaEspanha. Anais. Zaragoza: ANPAE, 2012.

DIZEU, Liliane Correia Toscano de Brito. CAPORALI, Sueli Aparecida. A língua de sinais constituindo o surdo como sujeito. Educação \& Sociedade, Campinas, vol. 26, n. 91, p. 583597, maio-ago. 2005.

DUARTE, Soraya Bianca Reis; CHAVEIRO, Neuma; FREITAS, Adriana Ribeiro de; BARBOSA, Maria Alves; PORTO, Celma Celno; FLECK, Marcelo Pio de Almeida Fleck. Aspectos históricos e socioculturais da população surda. História, Ciências, Saúde Manguinhos, Rio de Janeiro, v.20, n.4, p.1713-1734, out.-dez. 2013. 
GIL, Antonio Carlos. Métodos e técnicas de pesquisa social. $6^{\text {a }}$ Ed. São Paulo: Atlas, 2008.

GIROTO, Claudia Regina Mosca; PINHO, Gabriela Geovana; MARTINS, Sandra Eli Satoreto Oliveira. A disciplina de Libras na pedagogia: em análise a formação do formador. In: POKER, Rosimar Bortolini; MARTINS, Sandra Eli Sartoreto; GIROTO, Claudia Regina Mosca Giroto (Orgs.). Educação Inclusiva: em foco a formação de professores. Cultura Acadêmica: São Paulo, 2016, p. 153-172.

HONORA, Márcia. Inclusão educacional de alunos com surdez: concepção e alfabetização. São Paulo: Cortez, 2014.

JESUS, Clarice Karen de. A história da escolarização dos surdos: uma análise do passado até os dias atuais. Visão Universitária. v.3 p. 174-185. 2015.

LACERDA, Cristina . Broglia Feitosa. Um pouco da história das diferentes abordagens na educação de surdos. Cadernos CEDES, vol. 19, n. 46, Campinas, set. 1998.

LOPES, Raquel Aparecida; MOURA, Maria Cecília de; MASINI, Elcie Aparecida Fortes Salzano; TEIXEIRA, Maria Cristina Triguero Velos; RIBEIRO, Miriam Oliveira. O ensino da língua brasileira de sinais (LIBRAS) em cursos de graduação em pedagogia: uma possibilidade real? Trilhas pedagógicas.v. 6, n. 6, p. 212-228, ago. 2016.

LOUZADA, Juliana Cavalcante de Andrade. Inclusão Educacional: em foco a formação de professores de Educação Física. Marília, 2017. Dissertação (Mestrado em Educação), 127 p. Faculdade de Filosofia e Ciências da Universidade Estadual Paulista, 2017.

MAEDA, Lia. O impacto da disciplina de Libras na formação do pedagogo: uma análise da experiência dos alunos do curso de pedagogia da Universidade Estadual de Maringá. Trabalho de Conclusão de Curso apresentado ao Curso de Pedagogia da Universidade Estadual de Maringá, 2012.

MERCADO, Edna Aparecida. O significado e implicações da inserção de libras na matriz curricular do curso de pedagogia. In: ALBRES, Neiva de Aquino. Libras em estudo: ensinoaprendizagem. São Paulo: FENEIS-SP, 2012

OVIEDO, Alejandro. "Lengua de Señas", "Lenguaje de Signos", "Lenguaje Gestual", "Lengua Manual"? Razones para Escoger una Denominación. In: El Bilingüismo de los Sordos. Ministério de Educaciona Nacional - Instituto Nacional para Sordos, 1996.

PEREIRA, Maria Cristina da Cunha; VIEIRA, Maria Inês da Silva Vieira. Bilinguismo e educação de surdos, Revista Intercâmbio, São Paulo: LAEL/PUC, v. 19, p. 62-67. 2009.

SANTANA, Jane Aparecida de Souza. Análise das disciplinas de Libas nos cursos de Formação Inicial em pedagogia da UNESP. Presidente Prudente, 2013. Dissertação (Mestrado em Educação), 193p. Faculdade de Ciências e Tecnologia, da Universidade Estadual Paulista, 2013. 
SILVA, Carine Mendes da; SILVA, Daniele Nunes Henrique. Libras na educação de surdos: o que dizem os profissionais da escola. Psicologia Escolar e Educacional, São Paulo. V. 20, n. 1, p.33-43, jan-abr. 2016.

VIGOTSKI, Lev Semenovich. A Construção do Pensamento e da linguagem. Tradução de Paulo Bezerra.. São Paulo: Martins Fontes, 2000.

\section{Nota}

${ }^{1}$ Base de dados disponível no site http://emec.mec.gov.br/. 